\title{
Lightning protection techniques for roof-top PV systems
}

\begin{abstract}
In this paper, the lightning protection requirements of a typical residential building have been discussed and techniques have been provided to protect the building from both direct and indirect damages of lightning, with special attention to the protection of PV panels placed on the roof. These techniques include the designing challenges and also the type of devices which can be used to reduce the surge current flow and magnetic field. It has been shown that for buildings with roof top PV systems only the avoidance of lightning attachment to unprotected parts of the building is not sufficient. Lightning currents passing through the lightning protection system may still affect the PV power system through inductive coupling. Hence strategic placement of PV systems and shielding of conducting systems wherever possible has been recommended. It has also been envisaged that the impact of lightning on PV systems is directly related to the isokeraunic level of the region and elevation of the building. Several recommendations have been proposed in designing the air termination system for a roof with PV panels in high isokeraunic regions. Finally the building integrated photo voltaic (BIPV) projects which are conducted in Malaysia have been evaluated.
\end{abstract}

Keyword: BIPV; Lightning protection system; Roof-top PV system 